\title{
Seizures induced by music
}

\author{
A.O. Ogunyemi' and H. Breen ${ }^{2}$
}

\begin{abstract}
${ }^{1}$ Division of Neurology, Department of Medicine, Faculty of Medicine, Memorial University of Newfoundland and ${ }^{2}$ EEG Laboratory, The General Hospital, St John's, Newfoundland, Canada
\end{abstract}

\author{
Correspondence to: A.O. Ogunyemi, Division of Neurology, Department of Medicine, \\ Faculty of Medicine, Memorial University of Newfoundland, St John's, Newfoundland, \\ A1B 3V6 Canada
}

\begin{abstract}
Musicogenic epilepsy is a rare disorder. Much remains to be learned about the electroclinical features. This report describes a patient who has been followed at our institution for 17 years, and was investigated with long-term telemetered simultaneous video-EEG recordings. She began to have seizures at the age of 10 years. She experienced complex partial seizures, often preceded by elementary auditory hallucination and complex auditory illusion. The seizures occurred in relation to singing, listening to music or thinking about music. She also had occasional generalized tonic clonic seizures during sleep. There was no significant antecedent history. The family history was negative for epilepsy. The physical examination was unremarkable. CT and MRI scans of the brain were normal. During long-term simultaneous video-EEG recordings, clinical and electrographic seizure activities were recorded in association with singing and listening to music. Mathematical calculation, copying or viewing geometric patterns and playing the game of chess failed to evoke seizures.
\end{abstract}

Keywords: Auditory - Ictal - Music - Reflex epilepsy - Seizures - Telemetry - Video-EEG

\section{INTENSIVE STUDY OF SEIZURES INDUCED BY MUSIC}

Subsumed under the rubric of "reflex epilepsy" are seizures precipitated by sensory stimuli (Forster, 1977). Such seizures have been recorded in specific relation to elementary sensations such as visual, auditory, tactile and proprioceptive stimuli (Daube, 1966; Klass and Fischer-Williams, 1976). Even cognitive functions such as language (Geschwind and Sherwin, 1967) and mathematical calculation (Ingvar and Nyman, 1962; Wilkins $e t$ al., 1982) have been reported to provoke seizures.

The occurrence of seizures induced by music is well established (Critchley and Henson, 1977). It is unclear, however, whether it is the elementary auditory stimulation, the emotion engendered by the sensation or the intellectual processing of aspects of the music that is operative in evoking music-induced seizures. Little information is available in regard to the investigation of the electroclinical features of music-induced seizures using the technique of long-term simultaneous video-EEG recording. In studying our patient, we wanted to: (1) confirm that her seizures were related to music; (2) determine the localization of seizure onset; and (3) define the attribute of music related to the evocation of seizures.

\section{CASE REPORT}

This 27 year old woman experienced "ringing in the ears" when she attended her first violin lesson at the age of 10 years. Subsequent attendances at the violin and other music classes were associated with identical symptoms, sometimes progressing to "blackouts", even though she was performing exceedingly well and was believed to have special talent for music. Her aspiration to attend Music School as a voice major and piano minor was squashed because of progressive increase in the frequency and intensity of the seizures during the music classes.

For about 4 years, she only had either simple partial seizures alone or simple partial seizures progressing to complex partial; all associated with music. Subsequently, she began to experience infrequent generalized tonic clonic seizures during sleep. The simple partial seizures consisted of either the "ringing in the ears" or the auditory misperception during which the sound from a particular musical instrument would progressively increase in loudness. Often, during the escalation of the musical sound, she would lose awareness. During the period of altered consciousness, she might hum monotone of a song for a few seconds and consciousness would often be regained after $30-50 \mathrm{~s}$. The seizures were noted to occur when she 
was singing, listening to music or even thinking about music. Indeed, specific attention to rhythmical sounds such as from a microwave and air conditioner had resulted in seizures.

The general medical and neurological examinations were normal. CT and MRI scans of the brain were also normal. Multiple interictal EEG recordings were obtained. Most of these were normal although a few tracings showed sporadic spikes in the right frontal-anterior temporal region, during sleep. Treatment with optimal doses of phenytoin, carbamazepine and primidone failed to control the seizures provoked by music. The nocturnal generalized convulsions, however, only recurred on the few occasions when she was non-compliant with treatment.

\section{LONG-TERM SIMULTANEOUS VIDEO-EEG RECORDINGS}

During long-term simultaneous video-EEG recordings obtained via telemetry, five stereotyped complex partial seizures were recorded. Two occurred while she was singing and three while listening to music. One of these was recorded when she listened to the song "Happy Birthday to You". The seizures consisted of sudden loss of contact, forward head drop with moaning sound, drooping of the face and drooling of saliva.

The ictal electroencephalograms showed initial diffuse attenuation of background rhythms succeeded by focal, low-amplitude rhythmical fast activity with onset in the right frontal-anterior temporal region and subsequently involving the left frontal-anterior temporal region. Mathematical calculation, copying or viewing geometric patterns and playing the game of chess all failed to evoke seizures.

\section{DISCUSSION}

Webster's Ninth New Collegiate Dictionary (1990) defines "music" as "vocal, instrumental or mechanical sounds having rhythm, melody or harmony". As sound, music has elementary properties such as loudness and pitch. Because of the attributes of rhythm, melody or harmony, it can engender emotional response and is subject to cognitive or intellectual analysis. It is no wonder that opinions vary regarding the triggering factors and underlying brain mechanisms of seizures induced by music.

\section{Analysis of the seizure manifestations}

Our patient suffered from music-related partial seizures in the daytime and apparently spontaneous generalized tonic clonic seizures during sleep. The latter seizures were infrequent and readily controlled by anti-seizure agents. In contrast, the music-related partial seizures remained uncontrolled. Historically, the seizures began in relation to starting music lessons. The initial seizure manifestation consisted solely of simple auditory hallucination. Later during the disorder, she had an auditory illusion, consisting of increasing loudness of a portion of music. Forster (1977) described a similar experience in a patient who noted an "after image" of the music during her seizures.

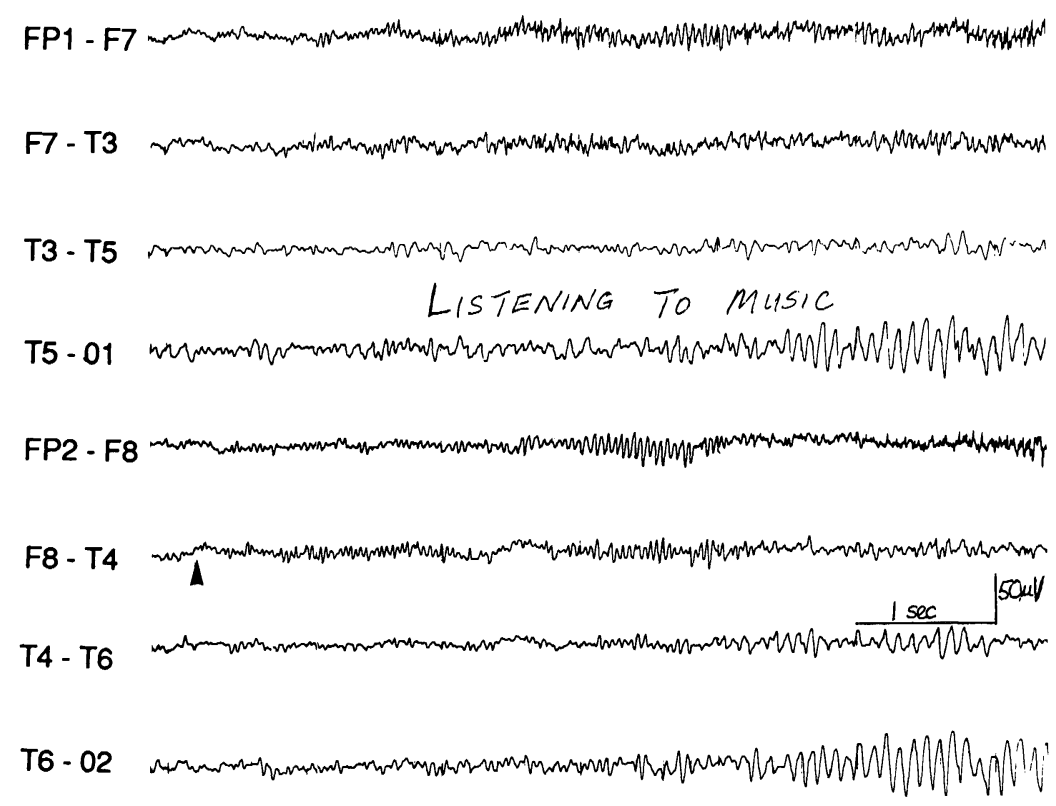

FIG. 1. EEG during seizure induced by listening to music. This EEG tracing shows onset of ictal discharge in the right fronto-temporal region. 


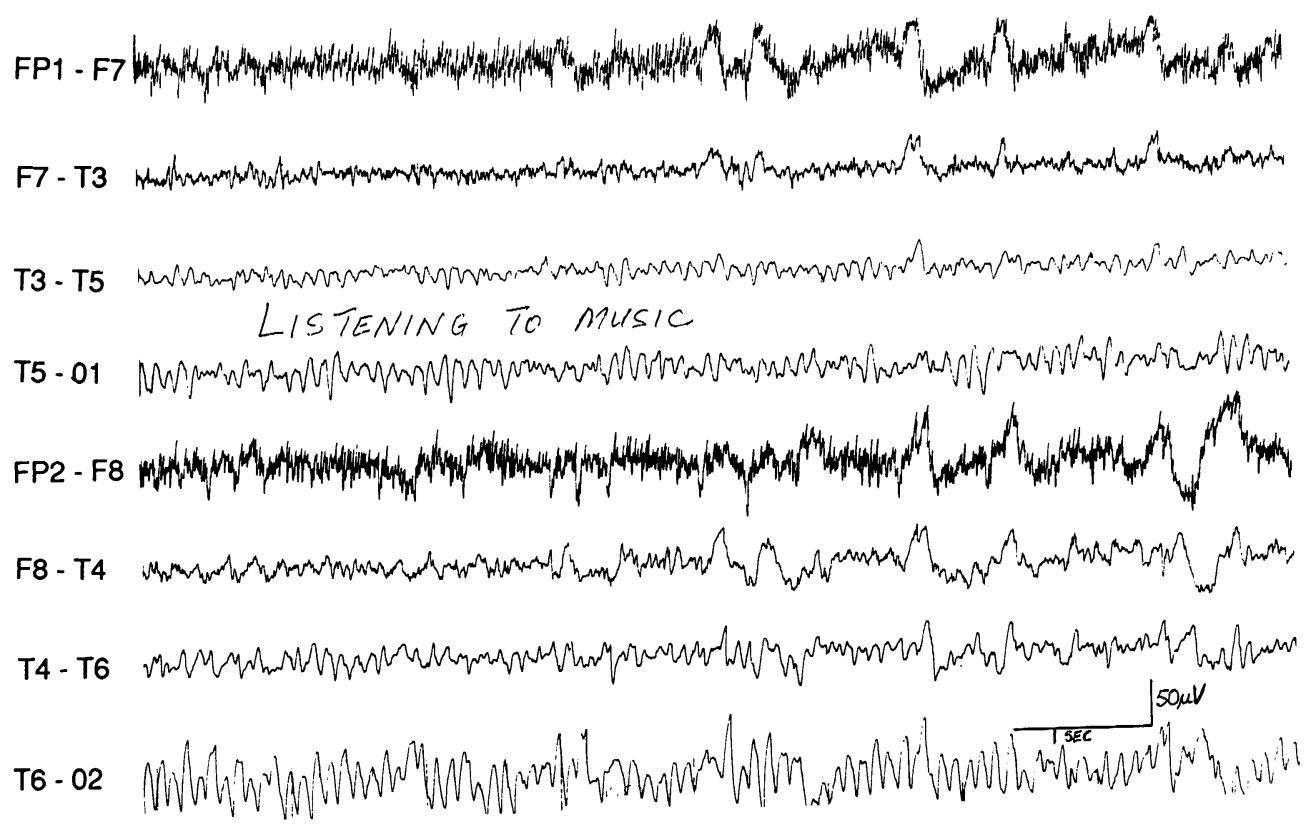

FIG. 2. EEG during seizure induced by listening to music. This EEG tracing depicts recurrent slow waves with maximum amplitude over the right frontal region.

Furthermore, our patient exhibited musical automatism, humming monotone of a song during altered consciousness.

\section{Music and cerebral lateralization}

Several reports attest to the importance of the right cerebral hemisphere for musical capacity. Clinical case studies by Luria et al. (1955) and Assal (1973) provide evidence of preservation of the ability for music following lesions of the dominant cerebral hemisphere which caused substantial language disturbance. Milner (1962), from her observations among patients who had temporal lobectomy, concluded that the right temporal lobe was specialized for some aspects of music. Kimura (1964), using dichotic listening tasks, observed that the left ear was superior to the right ear for the perception of melody. Using unilateral intracarotid sodium amylobarbitone, Bogen and Gordon (1971) and Gordon and Bogen (1974) noted that when the left cerebral hemisphere was injected, the patients became incapable of speaking but were able to sing. In contrast, right hemisphere injection caused loss of the ability to sing with preservation of language. By inference, these observations suggest that epileptic activation of the right cerebral hemisphere should be suspected in patients with seizures induced by music.

\section{Neurophysiological findings}

The results of neurophysiological findings have been inconsistent. Joynt et al. (1962) described left hemispherepredominant slow waves during music-provoked seizures.
Gastaut and Tassinari (1966), on the other hand, noted right temporal focus. In his series of music-induced seizures, Forster (1977) described ictal discharges arising from the left temporal region in some patients and localized to the right temporal region in others. Recently, Creutzfeldt and Ojemann (1989) found no lateralized differences in the activities of neurones of the left or right temporal lobes while the patients listened to music.

During music-induced seizures, the ictal discharges in our patient showed clear localized onset in the right frontotemporal region (Figs 1 and 2). This finding provides support for the many clinical studies which implicate the right cerebral hemisphere in musical function.

Impact of seizures induced by music

There is very little information on the long-term effect of music-induced seizures. In our patient, the seizures remained uncontrolled in spite of treatment with potent antiepileptic drugs. Furthermore, the seizure disorder dashed her hope and aspiration regarding her career choice. Therefore, we believe that music-induced seizures should not be regarded as benign.

\section{CONCLUSION}

Using long-term recording of simultaneous video and EEG, we confirmed that the partial seizures of our patient were induced by music. Other sensory and cognitive factors such as photic stimuli, geometric patterns and mathematical calculations did not provoke seizures. The 
seizure manifestations included simple auditory hallucination, complex auditory illusion and musical automatism. The seizures seemed to be related to the cognitive processing of music or rhythmical sounds.

\section{REFERENCES}

Assal G (1973) Aphasie de Wernicke chez un pianist. Revue Neurologique, 29, 251-254.

Bogen JE and Gordon HW (1971) Musical tests for functional lateralization with intracarotid amobarbital. Nature, 230, 524-525.

Creutzfeldt O and Ojemann G (1989) Neuronal activity in the human lateral temporal lobe: Activity changes during music. Experimental Brain Research, 77, 490-498.

Critchley M and Henson RA (1977) Music and the Brain. William Heinemann Medical Books, London.

Daube JR (1966) Sensory precipitated seizures: A review. Journal of Nervous and Mental Disease, 141, 524-539.

Forster FM (1977) Reflex Epilepsy, Behavioral Therapy and Conditional Reflexes. Charles C. Thomas, Springfield, IL.

Gastaut H and Tassinari CA (1966) Triggering mechanisms in epilepsy: The electroclinical point of view. Epilepsia, 7, 85-138.

Geschwind N and Sherwin I (1967) Language-induced epilepsy. Archives of Neurology, 16, 25-31.

Gordon HW and Bogen JE (1974) Hemispheric lateralization of singing after intracarotid sodium amylobarbitone. Journal of Neurology, Neurosurgery and Psychiatry, 37, 727-738.

Ingvar DH and Nyman GE (1962) Epilepsia arithmetics: A new psychologic trigger mechanism in a case of epilepsy. Neurology (Minneapolis), 12, 282-287.

Joynt RJ, Green D and Green R (1962) Musicogenic epilepsy. Journal of the American Medical Association, 179, 501-504.

Kimura D (1964) Left-right difference in the perception of melodies. Quarterly Journal of Experimental Psychology, 16, 355-358.

Klass DW and Fisher-Williams M (1976) Sensory stimulation, sleep and sleep deprivation. In: Handbook of Electroencephalography and Clinical Neurophysiology. Vol. 3, Part D. Activation and Provocation Methods in Clinical Neurophysiology (Ed. R. Naquet), pp. 5-73. Elsevier, Amsterdam.

Luria AR, Tsvetkova LS and Futer DS (1965) Aphasia in a composer. Journal of Neurological Science, 2, 288-292.

Milner B (1962) Laterality effects in audition. In: Interhemispheric Relations and Cerebral Dominance (Ed. VD Mountcastle), pp. 177-195. Johns Hopkins Press, Baltimore.

Webster's Ninth New Collegiate Dictionary (1990) MerriamWebster, Springfield, MA.

Wilkins AJ, Zifkin B, Andermann F and McGovern E (1982) Seizures induced by thinking. Annals of Neurology, 11, 608-612.

(Received 30 August 1993; accepted 7 September 1993) 


\section{Patient account}

I have had epilepsy since I was about 10 years old. I was not diagnosed as having epilepsy, however, until I was approximately 19 years old. Even at that time, my type of epilepsy was very vaguely understood. It was referred to as absence attacks, petit mal seizures, right temporal lobe epilepsy, as well as "something I would grow out of", and "the result of an over-protective mother". The fact that seizures seemed to frequently occur when I heard music made my type of epilepsy even less understood.

Evidence of the relation between my seizures and music began when I was approximately 10 years old. I was attending a violin lesson when I had a seizure. I described the experience as "a ringing in my ears", but only experienced this when the violin music was playing.

As I have always been heavily involved in music, I have always been surrounded by this medium. I aspired to reach Broadway for many years as a singer and, as a teenager, planned to attend Music School as a voice major and piano minor. This dream was not fulfilled as the frequency of my seizures became more and more intense. It soon became apparent that each time I would sing, I would most likely have a seizure. I quickly learned that Music School would not be a possibility for my future, and I reluctantly completed a Bachelor of Arts and Education. My involvement in voice and piano lessons also subsided as each lesson became wrought with seizures. By the time I reached 21, I had seen a host of neurologists and a neurosurgeon. The result of these visits was often discouraging and led to debates surrounding whether or not I would have a "right temporal lobectomy". I have never had brain surgery, and hope to never have to go that route. I feel there will be an answer to my epilepsy given time, and that a new medication will soon be discovered to which my very specific type of epilepsy will respond effectively. I will now briefly describe my present seizures to you.

For a long time, I felt that my seizures were related exclusively to music, however I began to experience seizures thinking about certain songs. The most problematic songs are those with recurring melodies such as "Happy
Birthday" and a variety of Christmas carols that we have all known since childhood. Some classical music pieces lend themselves to creating a "permissive mode" whereby a seizure will occur.

When I have a seizure it generally lasts $10-20$ seconds. It usually begins with the onset of some type of music or the thought of music, followed by a distortion of sound and a dream-like experience that causes me to see and hear people or things that are not really present. For example, I may be alone in a room that is adjacent to a room with a group of people. If I am singing or humming to myself and am alone, I will invariably have a seizure, and will also assume that the people who are in the adjacent room to me are comforting me as I am having this seizure. This never happens at all! Ninety-nine per cent of the time, other people are unaware of my seizures unless they are speaking directly to me. I tend to drop the sides of my mouth in a grimace, close my eyes a little and make a humming noise similar to a Gregorian Chant. This is generally the type of seizure I have in the day. There is one more interesting feature of this type of seizure. I tend to experience an aura just prior to a seizure. The aura is generally a quickening of my heartbeat followed by a feeling of nausea which is followed by a seizure.

Should I have a seizure at night when I am sleeping, it is far worse than the type of seizure I experience during the day. I have always thought that what I experience at night is a grand mal seizure as I shake or convulse, feel as though I am swallowing my tongue, and make frightening noises. These seizures generally last 30 seconds to a minute, and are followed by extreme fatigue and an intense headache the entire next day. I generally experience these seizures if I have missed medication, if I have been without sleep for a long time, if I am experiencing intense stress or if I have been at a late party and have had more than one alcoholic drink. These factors also seem to contribute to an increase in daily seizure activity.

B.H. 


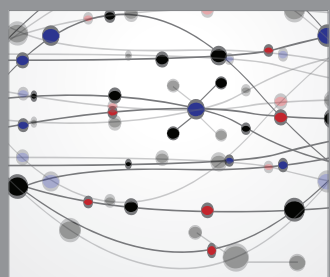

The Scientific World Journal
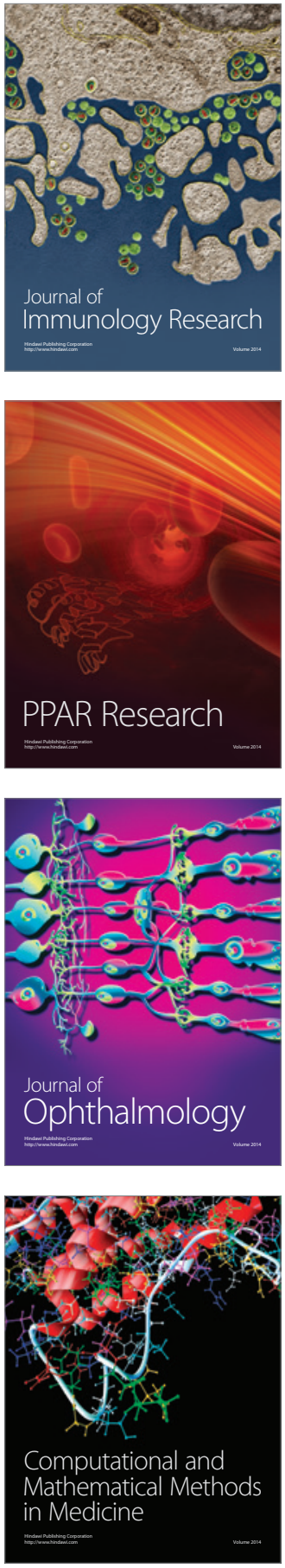

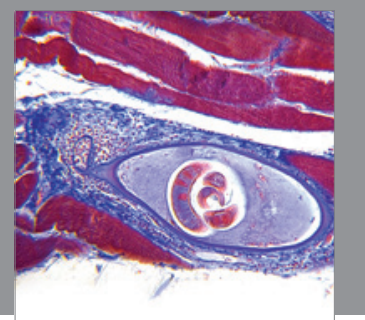

Gastroenterology

Research and Practice
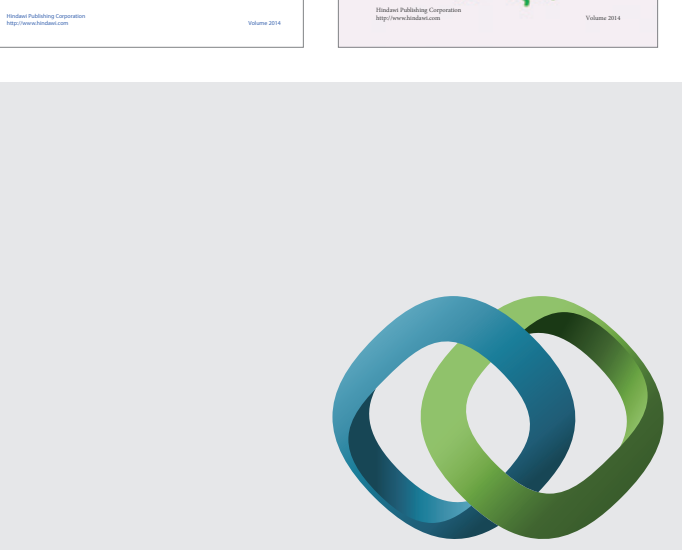

\section{Hindawi}

Submit your manuscripts at

http://www.hindawi.com
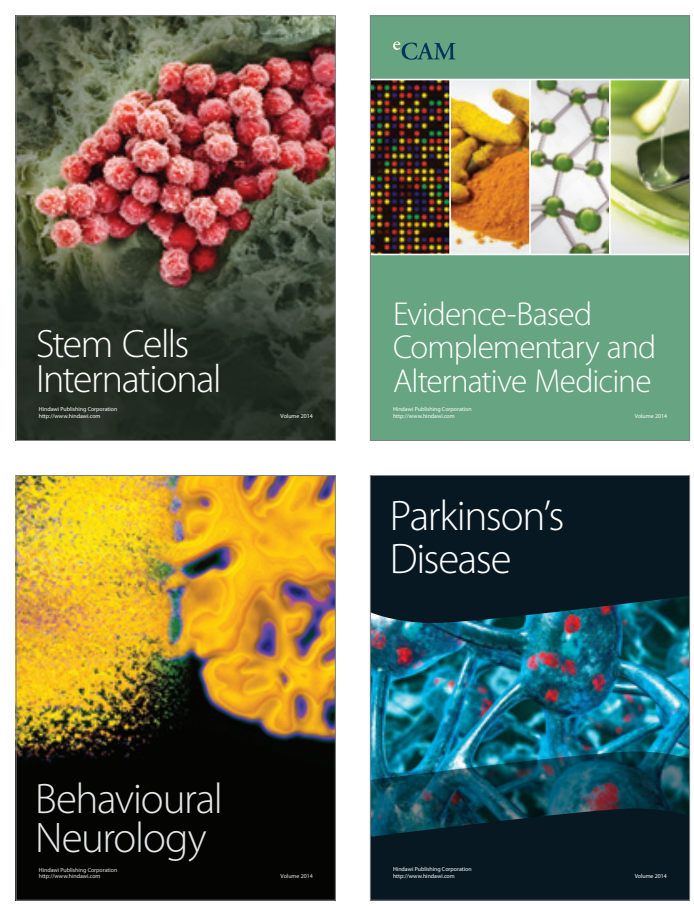

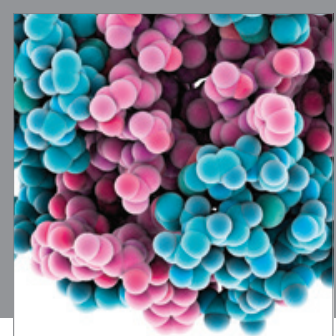

Journal of
Diabetes Research

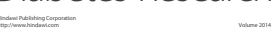

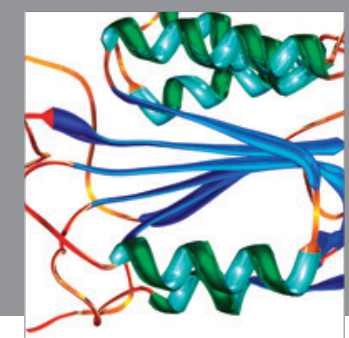

Disease Markers
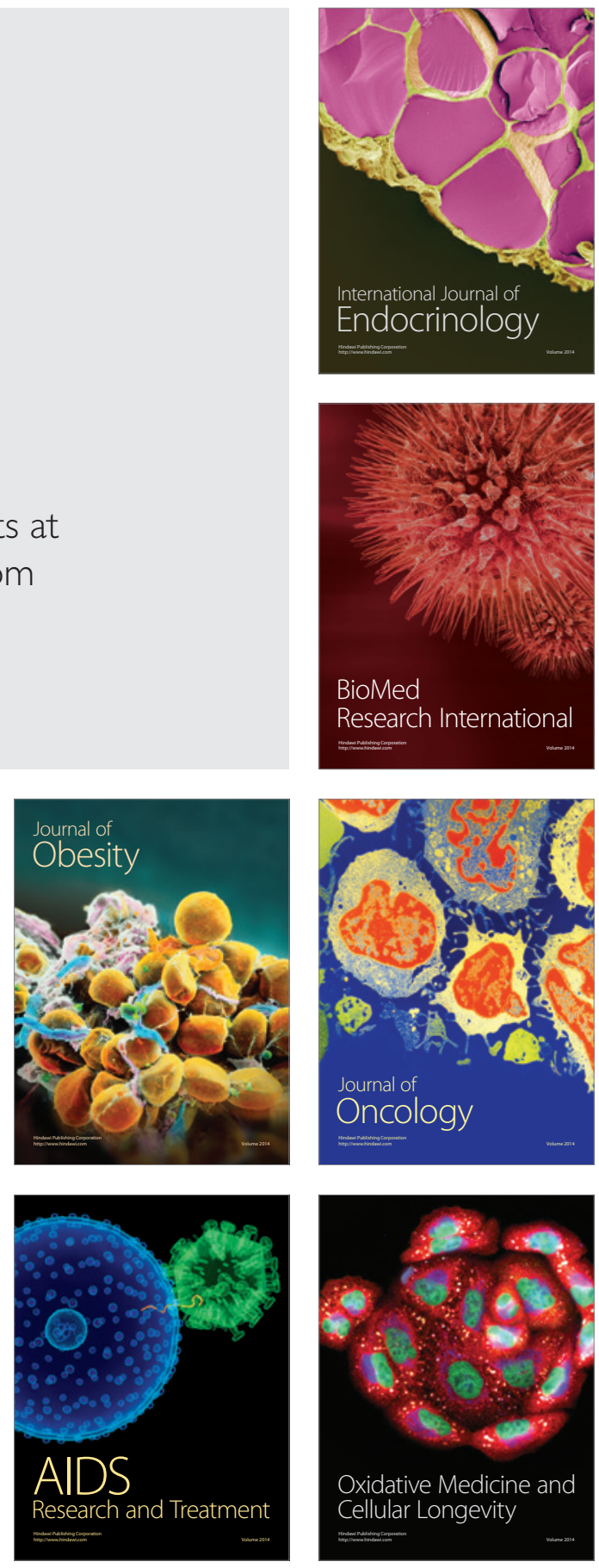